\title{
COMPLICAÇões locais NA PELE, RELACIONAdAS À APLICAÇÃO DE INSULINA
}

Daniela Gasparelli Camata ${ }^{1}$

Camata DG. Complicações locais na pele, relacionadas à aplicação de insulina. Rev Latino-am Enfermagem 2003 janeirofevereiro; 11(1):119-22.

A administração de insulina constitui um dos aspectos importantes na educação em diabetes. Este estudo enfoca as complicações locais na pele, relacionadas à aplicação de insulina. Foram entrevistados 51 portadores de diabetes mellitus, em uma instituição particular, no interior do Estado de São Paulo. Os resultados apontam que o hematoma foi a complicação mais freqüente e está relacionada, principalmente, à técnica incorreta de aplicação. Conclui-se que os profissionais de saúde precisam traçar estratégias efetivas que propiciem segurança aos sujeitos, a fim de prevenir as complicações na pele.

DESCRITORES: insulina, pele, enfermagem

\section{SKIN SITE COMPLICATIONS RELATED TO INSULIN APPLICATION}

Insulin administration is one of the important aspects in diabetes education. This study focuses on skin site complications related to insulin application. Fifty-one people with diabetes mellitus were interviewed at a private institution in São Paulo State. Results showed that hematomas were the most frequent complication and that they mainly resulted from the use of incorrect application techniques. It was concluded that health professionals must design effective strategies in order to provide safety to subjects and prevent skin complications.

DESCRIPTORS: insulin, skin, nursing

\section{COMPLICACIONES LOCALES EN LA PIEL RELACIONADAS A LA APLICACIÓN DE INSULINA}

La administración de insulina constituye uno de los aspectos importantes en la educación en diabetes. Este estudio enfoca las complicaciones locales en la piel relacionadas a la aplicación de insulina. Fueron entrevistados 51 portadores de diabetes mellitus en una institución particular en el interior del Estado de São Paulo. Los resultados muestran que el hematoma fue la complicación más frecuente y está relacionado principalmente con la técnica incorrecta de aplicación. Se concluye que los profesionales de salud necesitan establecer estrategias efectivas que propicien seguridad a los sujetos, con el fin de prevenir las complicaciones en la piel.

DESCRIPTORES: insulina, piel, enfermería

\footnotetext{
${ }^{1}$ Aluna do $7^{\circ}$ semestre do Curso de Graduação em Enfermagem, Bolsista do PIBIC/CNPq; Orientadora: Maria Lúcia Zanetti, Professor Doutor, email: zanetti@eerp.usp.br. Escola de Enfermagem de Ribeirão Preto da Universidade de São Paulo, Centro Colaborador da OMS para o desenvolvimento da pesquisa em enfermagem
} 
INTRODUÇ̃̃O

$\boldsymbol{R}$ econhecemos que, para a aplicação de insulina, são imprescindíveis métodos como escolha do instrumental adequado, domínio da técnica e rodízio dos sítios de aplicação na pele, entre outros. No entanto, é comum o portador de diabetes apresentar complicações e reações cutâneas, como lipodistrofia insulínica, lipohipertrofia, nódulos endurecidos, equimose, ardência, prurido ${ }^{(1-2)}$ e também alergia à insulina, a qual pode incidir no local da aplicação ou se caracterizar por uma reação sistêmica. Os sinais e sintomas de alergia localizada podem surgir de uma reação imediata com urticária, enduração e prurido; de uma reação intermediária, com lesões pruriginosas, endurecidas e dolorosas ou de uma reação tardia, apresentando lesões pruriginosas, endurecidas, eritematosas, com queimação local ${ }^{(3)}$.

A alergia sistêmica é rara, devido, principalmente, ao alto grau de pureza com que a insulina é fabricada e à introdução da técnica de recombinação genética, dando, esta última, origem à insulina humana ${ }^{(1,3)}$. Por outro lado, pesquisas sobre as complicações e reações locais na pele, relacionadas à aplicação de insulina, são escassas tanto na literatura nacional como na internacional. Assim, o presente estudo tem como objetivo descrever as complicações locais na pele do paciente, relacionadas à aplicação de insulina.

\section{MATERIAL E MÉTODOS}

Estudo descritivo, tipo "survey", realizado com uma amostra aleatória de 51 portadores de diabetes mellitus, tipos 1 e 2, todos adultos e usuários de insulina, atendidos no Centro Integrado de Endocrinologia e Diabetes de Ribeirão Preto - interior do Estado de São Paulo, no período de dezembro de 2000 a abril de 2001.

O instrumento que utilizamos para a coleta de dados foi um roteiro estruturado de entrevista, contendo as variáveis sociodemográficas e as relacionadas ao diagnóstico, tratamento e aos locais de aplicação de insulina. Inicialmente, informamos aos participantes da pesquisa seu objetivo e natureza, assegurando-Ihes o sigilo e o anonimato. A seguir, solicitamos o consentimento formal para sua participação no estudo. Para garantia da privacidade e da familiaridade com o ambiente, fizemos as entrevistas em uma sala reservada. Os dados obtidos por meio das entrevistas foram caracterizados e codificados manualmente, e, então, construiu-se um banco de dados a partir da formatação das planilhas no Programa Excel (para Windows 98, versão 7.0). A análise obedeceu às normas preconizadas para um estudo descritivo.

\section{RESULTADOS}

Dos 51 (100\%) entrevistados, 30 (58,8\%) eram do sexo feminino; 37 (72,5\%) possuíam idade superior a 40 anos; 37 (72,5\%) eram procedentes da cidade de Ribeirão Preto - SP; 17 (33,4\%) tinham o curso superior completo; 16 (31,4\%) eram aposentados; 27 (53\%) possuíam renda familiar superior a 15 salários mínimos; 17 (33,3\%) tinham diabetes tipo 1, e 34 (66,7\%), tipo 2. Ao analisarmos o tempo de doença, verificamos que 16 $(31,2) \%$ apresentavam a doença há mais de 15 anos; 18 $(35,3 \%)$ realizavam o tratamento apenas com dieta e insulina; $51 \%$ estavam em sobrepeso e obesidade, e $62,6 \%$ realizavam a auto-aplicação de insulina.

Analisando o tipo de instrumental, observamos que $74 \%$ dos entrevistados utilizavam a seringa descartável; $18 \%$ canetas; $6 \%$ seringas e canetas, e $2 \%$, injetores de insulina.

Em relação às complicações, constatamos que $33(64,7 \%)$ sujeitos apresentavam complicações no local de aplicação de insulina e 18 (35,3\%) não as apresentavam; dentre as complicações referidas, o hematoma foi citado por $33,3 \%$ dos sujeitos.

Do total de $33(100 \%)$ sujeitos que apresentaram complicações, 15 (45,5\%) são do sexo masculino, e 18 $(54,4 \%)$, feminino. Dos 18 (100\%) que não apresentaram complicações, 6 (33,3\%) são do sexo feminino, e 12 $(66,7 \%)$, masculino. Em relação à faixa etária, os dados mais expressivos apontam que a complicação ocorreu com mais freqüência nos portadores de diabetes mellitus com idade inferior a 50 anos (Tabela 1). 
Tabela 1 - Distribuição numérica e percentual das complicações na pele dos portadores de diabetes mellitus, no Centro Integrado de Endocrinologia e Diabetes, segundo sexo e faixa etária. Ribeirão Preto-SP, 2001

\begin{tabular}{|c|c|c|c|c|c|c|c|c|c|c|c|c|c|c|}
\hline \multirow[t]{3}{*}{ Complicação } & \multicolumn{4}{|c|}{ Sexo } & \multicolumn{10}{|c|}{ Faixa etária (anos) } \\
\hline & \multicolumn{2}{|c|}{ Masculino } & \multicolumn{2}{|c|}{ Feminino } & \multicolumn{2}{|c|}{$<40$} & \multicolumn{2}{|c|}{41 a 50} & \multicolumn{2}{|c|}{51 a 60} & \multicolumn{2}{|c|}{61 a 70} & \multicolumn{2}{|c|}{$>70$} \\
\hline & $\mathbf{N}^{\mathbf{o}}$ & $\%$ & $\mathbf{N}^{\mathbf{o}}$ & $\%$ & $\mathbf{N}^{\mathbf{o}}$ & $\%$ & $\mathbf{N}^{\mathbf{o}}$ & $\%$ & $\mathbf{N}^{\mathbf{o}}$ & $\%$ & $\mathbf{N}^{\mathbf{o}}$ & $\%$ & $\mathbf{N}^{\mathbf{o}}$ & $\%$ \\
\hline Sim & 15 & 45,5 & 18 & 54,4 & 12 & 36,4 & 5 & 15,1 & 6 & 18,3 & 5 & 15,1 & 5 & 15,1 \\
\hline Não & 6 & 33,3 & 12 & 66,7 & 2 & 11,0 & 1 & 5,6 & 2 & 11,0 & 4 & 22,4 & 9 & 50,0 \\
\hline
\end{tabular}

\section{DISCUSSÃO}

Os dados sociodemográficos indicam que a maioria dos portadores de diabetes mellitus possui habilidades cognitivas para aquisição de conhecimentos, bem como recursos materiais para manutenção do seu controle metabólico. Sendo assim, a nosso ver, parece que a escolaridade e a renda constituem fatores facilitadores para a adesão ao tratamento.

Em relação ao tipo de instrumental utilizado, chamou nossa atenção que somente $18 \%$ dos sujeitos utilizavam as canetas de insulina, fato preocupante, pois a renda familiar e a escolaridade não os impediam de obter e utilizar as canetas para aplicação da medicação ${ }^{(4)}$.

Estudos realizados em diversos países asseguram maior eficiência das canetas de insulina no tratamento do diabetes e, dentre os benefícios apontados, estão: menor complexidade na aplicação, maior exatidão da dose, menor risco de infecção subcutânea e menor desconforto; benefícios que tornam mais fácil a aderência à insulinoterapia ${ }^{(4-5)}$.

Quanto às complicações, o hematoma foi a mais freqüente. Essa alteração ocorre quando a agulha atinge um vaso sangüíneo superficial ou quando o ângulo da agulha se desvia, durante a inserção ou sua retirada ${ }^{(4,6-7)}$. A presença de "caroços" na pele pode ser ocasionada por injeções rápidas, volumosas ou superficiais.

Ao analisarmos a presença de complicação relacionada ao sexo e faixa etária, verificamos que não houve diferenças importantes. Isso nos leva a pensar que outras variáveis tais como os motivos das complicações referidas pelos sujeitos, relacionadas à técnica incorreta de aplicação de insulina e à falta de rodízio dos sítios de aplicação, podem estar contribuindo para o aparecimento de reações locais cutâneas.

Portanto, antes de caracterizarmos uma alergia à insulina, devemos afastar variáveis que podem contribuir para as reações cutâneas locais, como técnica inadequada de aplicação, higiene local precária e alergia ao álcool ou produtos utilizados na assepsia ${ }^{(2)}$. Assim, compreendemos que esforços precisam ser implementados para sanar as complicações apresentadas.

Uma das estratégias utilizadas para resolver esse problema é a elaboração de material didático, com demonstração em manequim, seguida da auto-aplicação, bem como orientação aos pacientes quanto ao rodízio dos sítios. Reconhecemos que a abordagem sistemática do rodízio do sítio, tal como a de aplicar as injeções em linha horizontal ou vertical, na mesma região, ajudam a evitar aplicações no mesmo ponto. Para o rodízio dos sítios de injeção, o paciente poderá utilizar, exclusivamente, os sítios do abdome ou os sítios de injeção em uma determinada área, na mesma hora do dia (área abdominal toda manhã e face posterior do antebraço toda tarde, por exemplo). Essas abordagens asseguram maior consistência na absorção e eficácia da insulina, se comparadas aos métodos anteriores de rodízio das injeções, que consistem em usar uma nova área do corpo para cada aplicação ${ }^{(1-2,4,6)}$.

\section{CONCLUSÕES}

Este estudo permitiu concluir que a principal complicação apresentada pelos sujeitos foi o hematoma, e que as complicações na pele estavam relacionadas, principalmente, à técnica inadequada para a aplicação de insulina.

Verificamos, ainda, que a maioria dos pacientes utilizavam a seringa descartável para aplicar a insulina. Assim, os profissionais de saúde precisam traçar estratégias efetivas que propiciem assegurar aos sujeitos, portadores de diabetes, segurança na aplicação de insulina, assim como informá-los sobre esquemas de rodízios de sítios de aplicação, a fim de prevenirem as complicações na pele, durante a aplicação de insulina. 


\section{REFERÊNCIAS BIBLIOGRÁFICAS}

1. Davidson MB. Diabetes mellitus: diagnóstico e tratamento. $4^{\mathrm{a}}$ ed. Rio de Janeiro: Revinter; 2001.

2. Costa AA, Almeida JS Neto. Manual de diabetes: alimentação, medicamentos, exercícios. $3^{\underline{a}}$ ed. São Paulo: Sarvier; 1988.

3. Silva MER. Alergia à insulina. Diabetes, Saúde \& Cia 2001; 13(3):3.

4. Souza CR, Zanetti ML. A prática de utilização de seringas descartáveis na administração de insulina no domicílio. Rev Latino-am Enfermagem 2001; 9(1):39-45.

5. Ferreira SRG. Números apontam maior eficácia das canetas. Diabetes, Saúde \& Cia 2001; 13(3):2.

6. Souza CR, Zanetti ML. Administração de insulina: uma abordagem fundamental na educação em diabetes. Rev Esc Enfermagem USP 2000; 34(3):264-70.

7. Souza CR, Zanetti ML, Ribeiro KP. Reutilização de seringas descartáveis: freqüência e custos para administração de insulina no domicílio. Rev Latino-am Enfermagem 2001; $9(5): 47-54$. 